Young Investigator Award

Topic: 3. Heart Failure and Cardiomyopathy

\title{
Cardiac Resynchronization is Associated with Reduction in the Rate of ICD Therapies, While Improves Ventricular Function
}

Gerard Oristrell, Enrique Galve, Juan Gabriel Acosta, Aida Rivera, Angel Moya, Ignacio Ferreira,

Jordi Perez-Rodon, David Garcia-Dorado

Hospital de la Vall d'Hebron - Cardiology

Keywords: ICD CRT-D

\section{Background}

Once ICD has been implanted, device therapies worsen prognosis.

\section{Hypothesis}

CRT-D may reduce number of first appropriate ICD therapy, and independent factors can be identified.

\section{Methods}

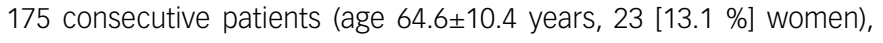
left ventricular ejection fraction (LVEF) $27.9 \pm 7.6 \%$ (range 10-50 \%), 97 of ischemic origin, were treated, according to standard indications, with an ICD (in 80 cases the device was CRT-D) and followed-up during $2.5 \pm 1.5$ years. Devices were placed for either primary $(n=95)$ or secondary prevention $(n=80)$.

\section{Results}

$44(25.1 \%)$ patients received at least one appropriate therapy, 11.55 (8.57-15.57) per 100 patient-years. In the multivariable analysis, indication for secondary prevention was associated with a higher risk of first appropriate therapy (HR 3.42 [1.36-8.57] $p=0.009$ ), and CRT-D was associated to a lower risk of first therapy (0.31 [0.11-0.88] $\mathrm{p}=0.027$ ). This reduction was present across all subgroups, even in patients in primary prevention $(\mathrm{p}=0.05)$, and although patients treated with CRT-D had significant lower ejection fraction and poorer NYHA class that their counterparts. In the follow-up, LVEF in

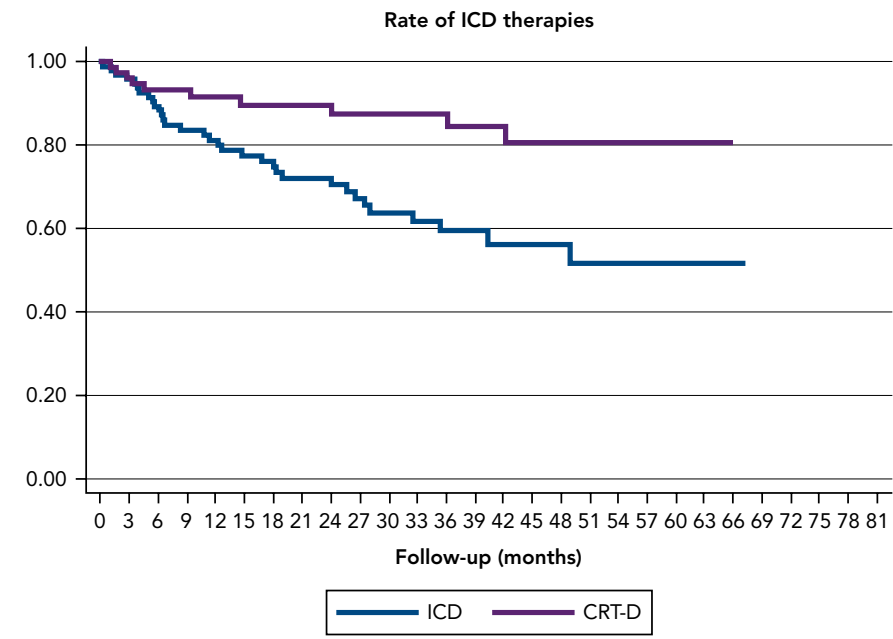

patients with CRT-D improved from $25.3 \%$ (5.6) to $37.0 \%$ (5.6) ( $p=0.001$ ). There were no differences in mortality in patients with and without CRT.

\section{Conclusion}

Although patients receiving CRT-D have a worse clinical profile, they receive less device therapies in comparison to those receiving an ICD; this reduction is associated with significant improvement in LV function.

\footnotetext{
Ermis C, Seutter R, Zhu AX, Benditt LC, VanHeel L, Sakaguchi S, Lurie KG, Lu F, Benditt DG. Impact of upgrade cardiac resynchronization therapy on ventricular arrhythmia frequency in patients with implantable cardioverter-defibrillators. J Am Coll Cardiol 2005:46:2258-63.

2. Manfredi JA, Al-khatib SM, Shaw LK, Thomas L, Fogel RI, Padanilam B, Rardon D, Vatthyam R, Gemma LW, Golden K, Prystowsky EN. Association between left ventricular ejection fraction post-cardiac resyncronization treatment and subsequent implantable cardioverter defibrillator therapy for sustained ventricular tachyarrhythmias. Circ Arrhythm Electrophysiol. 2013 Apr:6(2):257-64.
} 